\title{
Turizm Rehberliği Bölümü Öğrencilerinin Kişilik Özellikleri İle Rekreatif Faaliyetlere Katılım Engelleri İlişkisi
}

DOI: $10.26466 /$ opus. 634350

\author{
Ülker Çolakoğlu* - Hakan Atay ${ }^{* *}$ - Gülseren Yurcu*** \\ * Doç Dr.,Aydın Adnan Menderes Üniversitesi, Turizm Fakültesi, Konaklama İşletmeciliği , Aydın \\ E-Posta: ucolakoglu@adu.edu.tr \\ ORCID: 0000-0003-1265-3319 \\ ** Dr. Öğr. Üyesi, Adnan Menderes Üni., Turizm Fakültesi, Seyahat İşletmeciliği Böl, Aydın, \\ E-Posta: hakanatay@hotmail.com \\ ORCID: 0000-0003-4080-8250 \\ *** Doç. Dr. Akdeniz Üniversitesi, Turizm Fakültesi, Rekreasyon Yönetimi Bölümü, Antalya \\ E-Posta: gulserenyurcu@akdeniz.edu.tr ORCID:

\section{Öz}

Kişilik, bir insanın davranış ve düşüncelerini etkileyen unsurlardan meydana gelmektedir. Dolayısıyla insanın ayrılmaz bir parçasıdır. Rekreatif faaliyetlere katılma engelleri dikkate alındığında, bir insanın sahip olduğu kişiliğin, rekreatif faaliyetlere katılmada bir engel veya avantaj yaratıp yaratmayacağı dikkate alınması gereken bir araştırma sorusu olarak karşımıza çıkmaktadır. Bu araştırmanın amacı, Turizm Rehberliği bölümü öğrencilerinin kişilik özellikleri ve demografik faktörler ile rekreatiffaaliyetlere katıllm engelleri ilişkisini ortaya çıkarmaktır. Araştırma sürecinde nicel araştırma yöntemi kullanılmıştır. Araştırma evrenini iki devlet üniversitesi turizm fakültesi turizm rehberliği bölümünün öğrencileri oluşturmaktadır. Araştırma örnekleminde 289 öğrenciye anket uygulanmıştır. Veri toplamak için Kişilik Özellikleri ve Rekreatif Faaliyetlere Katılım Engelleri ölçekleri kullanılmıştır. Veri analizinde tanımlayıcı istatistiklerin yanı sıra, $t$ testi, ANOVA, korelasyon ve regresyon analizleri uygulanmıştır. Araştırma sonuçlarına göre, öğrencilerin rekreatif faaliyetlere katılım engelleri algilarının okul, cinsiyet ve rekreatiffaaliyet değişkenlerine göre farklılaştı̆̆̆, uyruk, yaş, sinıf ve gelir değişkenlerine göre ise farklılaşmadığı sonuçlarına ulaşılmıştır. Ayrıca, kişilik özellikleri ve rekreatif faaliyetlere katılım engelleri değişkenleri arasında pozitif ilişski olduğu; nazik kişilik özelliŭine sahip öğrencilerin rekreatif faaliyet katılım engeli algılarının daha yüksek olduğu tespit edilmiştir.

Anahtar Kelimeler: Turizm Rehberliği, Kişilik, Rekreasyon 


\title{
The Relationship Between Personality Characteristics of Tourism Guidance Department Students and Barriers to Participation in Recreational Activities
}

\begin{abstract}
Personality consists of factors that affect a person's behavior and thoughts. It is an inseparable part of man. Considering the obstacles to participating in recreational activities, it appears as a research question to consider whether personality will create an obstacle or advantage in participating in recreational activities. The aim of the study is to investigate the relationship between participation barriers to recreation activities and personality traits/demographic factors on students of Tourism Guidence Department. Quantitative research method was used in the research process. The research universe is consisted of students in two tourism faculties which provide tourism guidance education. The research sample consists of 289 students. Data were collected by questionnaire technique. Personality Traits and Recreational Activity Engagement scales were used to collect data. Descriptive statistics, $t$ test, ANOVA, correlation and regression techniques are used in data analysis. According to the findings of the study, it was found that the students of Aydin Adnan Menderes University (ADU) Tourism Guidance Department had higher perceptions of participation in recreational activities. In this study, it was found that female participants had more obstacles to participate in recreational activities. In both universities, it was found that female students' perceived barriers to participation in recreational activities were higher. As the number of foreign students is low, there is no statistically significant difference between the nationalities of the students and the barriers to participation in recreational activities. Similarly, no statistically significant difference was observed between the participants' ages, monthly income levels and classes and the barriers to participation in recreational activities.
\end{abstract}

Keywords: Tourism Guidence, Personality Traits, Recreation. 


\section{Giriş}

Bir zamanlar kişiliklerimiz yoktu (Mischel, 1968). İnsanın varoluşundan bu yana süren yolculuğu bütüncül bir çerçevede incelendiğinde, kişiliğin akademik bir kavram olarak ilk ne zaman tartışıldığını saptamak çok güçtür. Kişiliğin belirli özelliklere sahip olduğu fikri insanlığın tarihi kadar eskidir (Kavirayani, 2018). Milattan önce dördüncü yüzyılda yaşayan Aristo (384-322), insanda var olan kibir, alçak gönüllülük ve korkaklık gibi eğilimleri ve ahlaki olmayan davranışların temel belirleyicileri olarak görmüştür. Aristo bireysel farklılıkları tanımlarken, insanın bu eğilimlerdeki aşırı ve orta düzey seviyelerini göz önüne almıştır (Matthews, Deary ve Whiteman, 2003). Kişilik kavramının günlük dildeki anlamı ile bilimsel anlamı birbirinden farklıdır. Kişiliğin bilimsel bir terim olarak incelenmesi en erken 1930'lu yıllarda psikoloji bilimi içerisinde kendisine bir yer bulmasıyla başlamıştır. Bu ilk dönemlerde, gözlemlenemeyen dinamikler ve içsel dürtüler düşünülerek daha çok insan motivasyonu üzerinde durulmaktaydı. Deneysel psikologlar tüm bireyler için geçerli evrensel yasaları aradılar. Kişilik insanların birbirlerinden farklı ya da benzer olmalarına odaklandı (McAdams, 1997). Kişilik ile ilgili daha orijinal ve kapsayıc kuramlar 1975 yılından itibaren ortaya konulmuştur. Erken çocukluk dönemi, kalıtsal özellikler, davranış genetiği, çevresel faktörler ve çevre etkileşimi, pediatri ve DNA şifreleri gibi unsurlar da kişilik tartışmasına dahil edilmiştir (Buss ve Plomin, 2014).

Araştırmanın diğer kavramı olan rekreasyon ise daha çok boş zaman kavramı ile birlikte ele alınmaktadır. Boş zaman kavramı kısaca bireyin fiziksel ve sosyo-psikolojik ihtiyaçları doğrultusunda ve yine bu ihtiyaçları gidermek amaçlı ortaya konan bir davranışı ifade etmektedir. Dolayısıyla boş zaman bir çeşit aktivite ya da deneyim olarak görülmektedir (Lin, 1984). Rekreasyon kelimesinin sözcük yapısı incelendiğinde re-creation yani yeniden yapılandırma gibi bir anlam ortaya çıkmaktadır. Bir anlamda rekreasyon boş zamanı olan insanların, sahip oldukları bu boş zamanlarında gerçekleştirebilecekleri faaliyetlerle ilgilidir, yani boş zamanın belirli kullanış biçimlerini oluşturmaktadır (Karaküçük, 1999).

Boş zaman kullanımı ve rekreatif faaliyetlere katılım konusu sosyal gelişim ve toplumsal uyum açısından son derece önem taşımaktadır. Özellikle üniversite öğrencileri düzeyinde rekreatif faaliyetlere katılım konusunda var 
olabilecek engellerin saptanması ve bunların ortadan kaldırılması; öğrencilerin bu tür ihtiyaçlarını gidermek noktasında çözüm üretebilmek açısından önem arz etmektedir. Bu konuda daha önceden yapılmış olan çalışmalara bakıldığında, rekreatif faaliyetlere katılım engellerinin çevresel faktörler açısından incelendiği ve yapılan çalışmalarda daha çok hangi rekreasyon faaliyetlerinin tercih edildiğinin saptanmaya çalışıldığı görülmüştür (Mansuroğlu, 2002; Müderrisoğlu ve Uzun, 2004; Balc1 ve İlhan, 2006; Tekin, Ylldız, Akyüz ve Uğur, 2007; Demirel ve Harmandar, 2009; Tütüncü, Aydın Küçükusta, Avaı ve Taş, 2011; Kılıç ve Şener, 2013; Ekinci, Kalkavan, Gündüz ve Üstün, 2014). Rekreatif faaliyetlere katılım ile kişilik özellikleri arasında yapılan çalışmalar son derece sınırlıdır (Slavson, 1948; Nias, 1985). Bu çalışmada kişilik özellikleri ile rekreatif faaliyetlere katılım engelleri arasındaki ilişkinin ortaya konulması amaçlanmıştır. Böylece üniversite öğrencilerin kişilik yapılarına göre rekreatif faaliyetler daha etkin bir şekilde tasarlanabilir veya farklı kişilik yapısına sahip öğrencilerin uygun rekreatif faaliyetlere yönlendirilmesi sağlanabilir.

\section{Kavramsal Çerçeve}

\section{Kişilik Özellikleri}

Kişiliğin genel geçer ve tüm kültürleri kapsayan bir tanımını yapmak çok güçtür. Kişilik kısaca bir insanın duyuş, düşünüş ve davranış biçimlerini etkileyen unsurların toplamı olarak tanımlanabilir. Bu unsurlar kişinin genlerinde var olan biyolojik ve psikolojik özellikler, güdüler, yetenekler, duygular, istek ve alışkanlıklar ve davranışlar gibi çeşitli faktörlerdir. Kişilik bir bakıma bunların bileşiminden meydana gelmektedir (Tınar, 1999; Yelboğa, 2006). Bu bileşim her insanda aynı formülde meydana gelmez, dolayısıyla kişilik kavramı bireyi diğer bireylerden ayırıc bir özelliğe sahiptir. Kişinin başkalarıyla olan iletişiminde ortaya koyduğu tepkileri ve kendisini gösterme biçimini belirler (Köknel, 1984; Morgan, 1998). Buradan yola çıkarak kişiliği bireyin dış çevresindeki değişkenlere tepki verirken farklılığını ortaya koyduğu tutum ve davranışların temelini oluşturan, kişiye özgü olan ve mümkün olduğunca değişmeyen, tutarlı ve kararlı özellikler bütünü olarak tanımlamak mümkündür (McCrae ve Costa, 1990; Burger, 2006; Özarslan, 2010). 
Kişilik kavramının tartışıldığı alan yazın incelendiğinde, kişiliğin hangi özellikler ile tanımlanabileceği konusunda farklı yaklaşımların ortaya konulduğu görülmektedir. Kişilik özelliklerinin üçlü, beşli ve yedili faktörlerle ölçeklendirildiği farklı yaklaşımlar söz konusudur. Örneğin kontrol eksikliği, stres tepkisi ve odaklanmadan oluşan üç faktörlü (Youn ve Faber, 2000); d1şadönüklük/içedönüklük, hasımlık/uzlaşmacılık, vicdanlılık, sinirlilik/duygusal tutarlılık ve keskin zekalılı (Digman, 1989); nevrotiklik, içedönüklük/dışadönüklük, açıklık, uyumluluk, özdisiplin (McCrae ve Costa, 1990), ve dışadönüklük, naziklik, vicdanlılık, nevrotiklik, açıklıkdan oluşan (John ve Srivastava, 1999) beş faktörlü; uyumluluk, başarma arzusu, sosyallik, canayakınlık, ferasetlilik, düşüncelilik ve okul başarısından oluşan (Driskel, Hogan, Salas ve Hoskin, 1994) yedi faktörlü yaklaşımlar görülebilmektedir. Ancak genel olarak bakıldığında beş faktörlü modellerin kişilik özelliklerini açıklamada daha destekleyici modeller ortaya koyduğu konusunda yaygın bir fikir birliği görülmektedir (Goldberg, 1990; Taggar, 1999; Burger, 2006; McCrae ve Costa, 2008; Horzum, Ayas ve Padır, 2017).

\section{Rekreatif Faaliyetlere Katılım Engelleri}

İnsanların çeşitli uzunluklarda ve farklı sürelerde boş zamanları ortaya çıkabilir. İnsanlar bu boş zamanlarında uzaklaşmak, dinlenmek, hava değişimi, gezme-görme, sağlık, beraber olma, heyecan duyma, farklı deneyimler elde etme gibi amaçlarla, ev dışında veya ev içinde, açık veya kapalı alanlarda, pasif veya aktif şekilde, şehirde veya kırsal alanlarda etkinliklere katılmaktadırlar. Rekreasyon, insanların dinlenmek ve hoşça vakit geçirmek amacıyla (Mansuroğlu, 2002) boş zamanlarında yaptıkları etkinlikleri ifade eden bir kavramdır (Karaküçük, 1991). Aktif rekreasyon basketbol, golf, tenis, tırmanma gibi sportif faaliyetlere katılmak, kamp yapmak gibi kişisel etkinliğin olduğu faaliyetleri içerirken; pasif rekreasyon ise barbekü yapmak, doğal yaşam parklarını ziyaret etmek ve doğa gezileri gibi aktiviteleri kapsamaktadır (Schwilgin, 1974; Mansuroğlu, 2002).

Daha önceden bu konuda yapılmış çalışmalarda, üniversite öğrencilerinin rekreatif faaliyetlere katılmada: kişinin fizyolojik özellikleri, arkadaş çevresi, kişinin kendine olan güveni, alanların durumu, olumsuz duygular, ekonomik durum, yan unsurlar, örgütsel unsurlar ve ruhsal durum gibi bazı engeller ön plana çıkmıştır (Müderrisoğlu, Kutay ve Eşen; 2005; Tütüncü, Aydın, 
Küçükusta, Avcı ve Taş, 2011). Ayrıca üniversitelerin sosyal olanaklarının yetersizliği, öğrencilerin kendilerini daha çok yerleşke dışında mutlu hissetmeleri, genel olarak yerel yönetimler tarafından rekreasyon alanlarına gereken önemin verilmemesi, ders yoğunluğu, etkinlik gün ve saatlerinin ders saatleriyle uyumsuz olması, etkinliklerin ilgi çekici olmaması, maddi yetersizlikler, arkadaş çevresinin ilgisizliği (Lapa ve Ardahan, 2009; Kılıç ve Şener, 2013); tesis-hizmet-ulaşım ile birey psikolojisi, sosyal ortam ve bilgi eksikliği de (Demirel ve Harmandar, 2009; Ekinci, Kalkavan, Gündüz ve Üstün, 2014) saptanan diğer engeller arasındadır. Yedi üniversiteden 1318 kişi üzerinde yapılan kapsamlı bir çalışmada öğrencilerin rekreatif faaliyet seçiminde sırasıyla: futbol, fitness, müzik dinlemek, tavla oynamak ve bilgisayar kullanmak seçeneklerini tercih ettikleri saptanmıştır (Balcı ve İlhan, 2006). Bu sonuç da öğrencilerin yerleşkeye bağımlı olmayan ve pasif olarak nitelenecek aktivitelere yöneldiklerini ortaya koymaktadır. Bir öğrenci yurdunda yapılan çalı̧̧mada da, öğrencilerin yurtta kalmaya başladıktan sonra (özellikle kız öğrencilerin) rekreasyon alışkanlıklarında olumsuz değişmeler olduğu; yeterli rekreatif ortamın sunulmadığı, personelin boş zaman ve rekreasyon konusunda bilinçsiz ve ilgisiz olduğu, tesislerin yetersiz olduğu saptanmıştır (Tekin, Yıldız, Akyüz ve Uğur, 2007). Bir başka çalışmada, cinsiyet ve gelir düzeyinin rekreatif faaliyetlere katılımı etkilediği belirtilmiştir. Futbol, voleybol, basketbol, masa tenisi, bilardo, balık tutmak, avlanmak ve güreş erkekler ve gelir düzeyi düşük olan katılımcılar tarafından en çok tercih edilen rekreasyonel faaliyetlerdir. Bunun yanında alışveriş yapmak, kır gezilerine katılmak, radyo dinlemek kadınlar tarafından daha çok tercih edilen rekreasyonel faaliyetler olarak saptanmıştır (Müderrisoğlu ve Uzun, 2004).

\section{Yöntem}

Akdeniz Üniversitesi ve Aydın Adnan Menderes Üniversitesi Turizm Rehberliği Bölümü öğrencilerinin kişilik özellikleri ve demografik faktörleri ile rekreatif faaliyetlere katılım engelleri arasındaki ilişkiyi belirlemek amacıyla yapılan bu araştırmada nicel araştırma yaklaşımı tercih edilmiştir. Araştırma ilişkisel tarama modelindedir. Araştırmanın uygulama alanı olarak Akdeniz Üniversitesi ve Aydın Adnan Menderes Üniversitesi Turizm Rehberliği Bölümüne devam eden öğrenciler seçilmiştir. Araştırma alanı olarak bu üniversitelerde öğrenim gören öğrencilerinin seçilme sebebi, her iki üniversitenin 
de sahil şeridinde ve bir turistik destinasyonda olması; öğrencilerin boş zaman değerlendirme alternatiflerinin daha fazla olmasıdır. Araştırmanın evrenini Akdeniz Üniversitesi ve Aydın Adnan Menderes Üniversitesi Turizm Rehberliği Bölümüne aktif devam eden toplam 399 öğrenci oluşturmaktadır. Araştırmada örneklem seçiminde tesadüfi örnekleme yöntemlerinden basit rassal örneklem yöntemi belirlenmiştir. Araştırma kapsamında 289 öğrenciye gönüllülük esası ile ulaşılmıştır. Veriler 2018 yılı Ekim-Kasım aylarında anket tekniği ile toplanmıştır. Anket tekniği nicel araştırmalarda kısa zamanda çok fazla katılımcıya, daha az maliyetle ulaşma olanağı sağladığı için tercih edilmiştir. Anketler öğrencilerin ders bitiminde sınıfta zaman ayırmaları talebiyle araştırmacıların gözetiminde uygulanmıştır. Araştırma verilerini toplamak amacıyla oluşturulan anket, demografik ve tanıtıcı değişkenler (okul, yaş, cinsiyet, uyruk, sınıf, aylık gelir durumu, rekreatif faaliyet), kişilik özellikleri ölçeği, rekreatif faaliyetlere katılım engelleri ölçeğinin yer aldığı üç bölümden oluşmaktadır.

Çok değişkenli analizlerde verilerin normal dağılıp dağılmadığını belirlemek için çarpıklık (skewness) (-.678) ve basıklık (kurtosis) $(1,419)$ değerlerine bakılmış, ayrıca Kolmogorov-Smirnov testi uygulanmıştır. Kurtosis ve Skewness değerleri -1.5 ile +1.5 olduğu zaman normal dağılım olduğu kabul edilmektedir (Tabachnick ve Fidell, 2013). Test sonuçlarına göre verilerin normal dağılıma sahip olduğu görülmüsstür. Verilerin elde edilmesinde tanımlayıcı istatistiklerin yanısıra normal dağılım gösterdiği için parametrik testler $(\mathrm{t}$ test, ANOVA) tercih edilmiştir. Araştırmada kullanılan ölçümlerin güvenilirliğini ölçmek için Cronbach Alpha güvenilirlik analizi, ölçeklerin yapı geçerliliğinin sınanabilmesi için doğrulayıc faktör analizi uygulanmıştır. Araştırmada kullanılan ölçümlerin genel geçerlilik ve güvenilirlik analizinde Cronbach Alpha katsayısı 0.86'dır. Kişilik özellikleri ölçeğinin Cronbach Alpha katsayısı 0.65; rekreatif faaliyetlere katılım engelleri ölçeğinin Cronbach Alpha katsayısı 0.91'dir. Değişkenlerin ilişkisini belirlemek için Pearson korelasyon analizi, değişkenlerin birbirleri üzerindeki etkisini belirlemek amacıyla çoklu regresyon analizinden yararlanılmıştır. Araştırmada kullanılan ölçeklerle ilgili bilgiler şu şekildedir: 


\section{Kişilik Özellikleri Ölçeği}

Turizm rehberliği öğrencilerinin kişilik özelliklerini belirlemek amacıyla John, Donahue ve Kentle (1991) tarafından geliştirilen ve John ve Srivastava'nın (1999) çalışmalarında kullandıkları 44 ifade ve 5 boyuttan (dışadönüklük, naziklik, vicdanlılık, nevrotiklik, açıklık) oluşan Beş Faktör Kişilik Ölçeği (BFKÖ) kullanılmıştır. Katılımcılar ifadelere yönelik görüşlerini: (1) "Hiç Katılmıyorum", (2) “Çok Az Katılmıyorum", (3) "Kararsızım", (4) “Oldukça Katıllyorum", (5) "Çok Fazla Katılıyorum" şeklinde 5'li likertten oluşan bir ölçekle belirtmişlerdir. 44 ifadenin boyutlara dağılımı ve ters puanlanan ifadeler şu şekildedir; (Dışadönüklük: 1, 6R, 11, 16, 21R, 26, 31R, 36, Naziklik: 2R, 7, 12R, 17, 22, 27R, 32, 37R, 42, Vicdanlllık: 3, 8R, 13, 18R, 23R, 28, 33, 38, 43R, Nevrotiklik: 4, 9R, 14, 19, 24R, 29, 34R, 39, Açıklık: 5, 10, 15, 20, 25, 30, 35R, 40, 41R, 44).

\section{Rekreatif Faaliyetlere Katılım Engelleri Ölçeği}

Öğrencilerin rekreatif faaliyetlere katılım engelleri algısının belirlenebilmesi için Gürbüz ve Karaküçük (2007) tarafından geliştirilen 28 ifadeden oluşan "Rekreatif Faaliyetlere Katılım Engelleri Ölçeği" kullanılmıştır. Ölçekteki maddeler, "Hiç Etkilemez (1)", "Etkilemez (2)", "Kararsızım (3)", "Etkiler (4)" ve "Çok Etkiler (5)" şeklinde 5’li likert tipi ölçekle değerlendirilmektedir. Ölçek ifadeleri faktör analizi sonucunda tek faktör altında toplanmıştır.

Araştırma hipotezleri şu şekildedir;

- Hı:Turizm rehberliği öğrencilerinin cinsiyet, yaş, uyruk, gelir düzeyi ile rekreatif faaliyet katılım engelleri arasında istatistiksel açıdan anlamlı bir farklılaşma vardır.

- $\mathrm{H}_{2}$ : Turizm rehberliği öğrencilerinin okulları ile rekreatif faaliyet katılım engelleri arasında istatistiksel açıdan anlamlı bir farklılaşma vardır.

- $\mathrm{H}_{3}$ : Turizm rehberliği öğrencilerinin sınıfları ile rekreatif faaliyet katılım engelleri arasında istatistiksel açıdan anlamlı bir farklılaşma vardır.

- $\mathrm{H}_{4}$ :Turizm rehberliği öğrencilerinin katıldıkları rekreatif faaliyetler ile rekreatif faaliyet katılım engelleri arasında istatistiksel açıdan anlamlı bir farklılaşma vardır.

- Hs:Turizm rehberliği öğrencilerinin kişilik özellikleri ve rekreatif faaliyet katılım engelleri arasında pozitif ilişki vardır. 
- $\mathrm{H}_{6}$ : Turizm rehberliği öğrencilerinin kişilik özellikleri, rekreatif faaliyet katılım engellerini pozitif etkilemektedir.

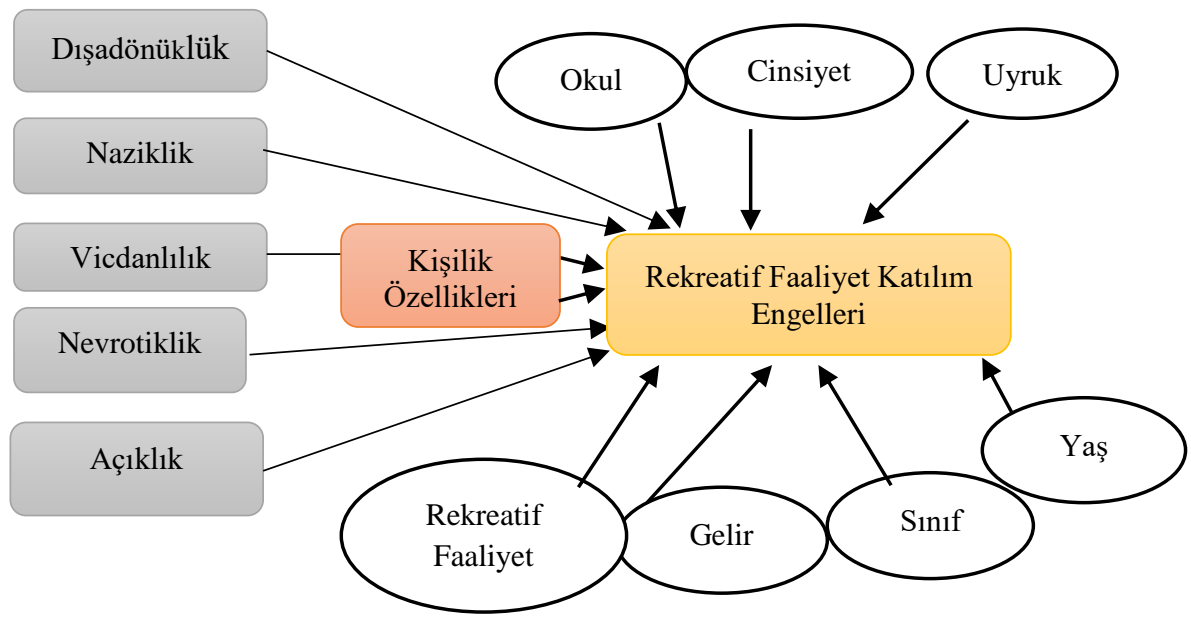

\section{Şekil 1.Araştırma Modeli}

Şekil 1'de de görüldüğü gibi araştırma modelinin merkezinde kişilik özelliklerinin rekreatif faaliyet engelleri ile olan ilişkisi yer almaktadır. Ayrıca rekreatif faaliyetlere katılım engellerinin daha iyi yorumlanabilmesi için bazı demografik değişkenlerle ve tercih edilen rekreatif faaliyetle olan farklılaşma düzeyleri de incelenmiştir.

\section{Araştırma Bulguları}

\section{Demografik ve Tanıtıcı Bilgilere İlişkin Bulgular}

Araştırma katılımcılarının \%67,1'ini Aydın Adnan Menderes Üniversitesi, \%32,9'unu Akdeniz Üniversitesi Turizm Fakülteleri Turizm Rehberliği öğrencileri oluşturmaktadır. Öğrencilerin \%53,6'sı 18-23 yaş aralığın da, \%46's1 k1z, \%54'ü erkek, \%95,2'si T.C. uyruklu, \% 39,4'ü 1.sınif, \% 21,1'i 2.sinif, \%23,5'i 3.sınıf, \%13,5'i 4.sınıf, \%70,5'i 500-1000 TL gelire sahiptir. Öğrencilerin \%71,3'ünün boş zamanlarında katıldıkları herhangi bir rekreatif faaliyeti yok, 


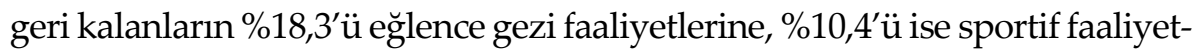
lere katılmaktadır. Katılımcıların kişisel bilgilerine ilişkin veriler Tablo 1'de gösterilmektedir.

Tablo 1. Demografik ve Tanıtıcı Bilgilere İlişkin Bulgular

\begin{tabular}{|c|c|c|c|c|c|c|c|}
\hline Değişken & & $\mathrm{f}$ & $\%$ & Değişken & & $f$ & $\%$ \\
\hline \multirow[b]{2}{*}{ Okul } & Akdeniz Üni. & 95 & 32,9 & \multirow[b]{2}{*}{ Cinsiyet } & $\mathrm{K}_{1 \mathrm{z}}$ & 133 & 46,0 \\
\hline & $\begin{array}{l}\text { Adnan } \\
\text { Menderes Üni. }\end{array}$ & 194 & 67,1 & & Erkek & 156 & 54,0 \\
\hline \multirow{16}{*}{ Yaş } & 18 & 28 & 9,7 & \multirow{3}{*}{ Uyruk } & T.C. & 275 & 95,2 \\
\hline & 19 & 33 & 11,4 & & Diğer & 13 & 4,5 \\
\hline & 20 & 38 & 13,1 & & Kayıp değer & 1 & 3 \\
\hline & 21 & 25 & 8,7 & \multirow{5}{*}{ Sinif } & 1 & 114 & 39,4 \\
\hline & 22 & 18 & 6,2 & & 2 & 61 & 21,1 \\
\hline & 23 & 13 & 4,5 & & 3 & 68 & 23,5 \\
\hline & 24 & 3 & 1,0 & & 4 & 39 & 13,5 \\
\hline & 25 & 3 & 1,0 & & Kayıp değer & 7 & 2,4 \\
\hline & 26 & 1 & 3 & \multirow{6}{*}{ Aylık gelir } & 500 ve altı & 90 & 31,1 \\
\hline & 28 & 1 & 3 & & $500-1000$ & 114 & 39,4 \\
\hline & 29 & 1 & 3 & & $1001-1500$ & 21 & 7,3 \\
\hline & 40 & 1 & 3 & & $1501-2000$ & 25 & 8,7 \\
\hline & 45 & 1 & 3 & & 2001 ve üzeri & 34 & 11,8 \\
\hline & 46 & 1 & 3 & & Kayıp değer & 5 & 1,7 \\
\hline & 48 & 1 & 3 & \multirow{3}{*}{ Faaliyet } & Yok & 206 & 71,3 \\
\hline & Kayıp değer & 121 & 41,9 & & $\begin{array}{l}\text { Eğlence Gezi } \\
\text { Faaliyetleri }\end{array}$ & 53 & 18,3 \\
\hline \multirow[t]{2}{*}{ Toplam } & & 289 & 100 & & Spor Faaliyetleri & 30 & 10,4 \\
\hline & & & & \multicolumn{2}{|l|}{ Toplam } & 289 & 100 \\
\hline
\end{tabular}

\section{Araştırma Hipotezlerine İlişkin Bulgular}

Araştırma hipotezlerine ilişkin elde edilen bulgular ve yorumlar aşağıda verilmiştir.

Tablo 2. Turizm Rehberliği Öğrencilerinin Okullarna Göre Rekreatif Faaliyetlere Katılım Engelleri

\begin{tabular}{lllllll}
\hline & $\mathrm{N}$ & $\bar{x}$ & Standart Sapma & $\mathrm{t}$ & $\mathrm{df}$ & $\mathrm{p}$ \\
\hline Akdeniz Üni. & 84 & 3,5817 &, 59755 & \multirow{2}{*}{2,330} & \multirow{2}{*}{276} & \multirow{2}{*}{0,021} \\
\hline Aydın Adnan Menderes Üni. & 194 & 3,7722 &, 63767 & & & \\
\hline
\end{tabular}

Katılımcıların rekreatif faaliyet katılım engelleri algılarının Akdeniz Üniversitesi Turizm Rehberliği Bölümü ortalaması ( $\bar{x}=3,5817)$ ve Aydın Adnan 
Menderes Üniversitesi Turizm Rehberliği Bölümü ortalaması ( $\bar{x}=3,7722)$ olarak saptanmıştır. Anlamlılık için yapılan $t$ testine göre, öğrencilerin okulları ile rekreatif faaliyet katılım engelleri algiları arasındaki fark $(t=-2,330$, $\mathrm{p}<0,05)$ anlamlı bulunmuştur. Bu durumda, Aydın Adnan Menderes Üniversitesi Turizm Rehberliği Bölümü öğrencilerinin rekreatif faaliyet katılım engelleri algılarının daha yüksek olduğu tespit edilmiştir.

Tablo 3. Turizm Rehberliği Öğrencilerinin Cinsiyetlerine Göre Rekreatif Faaliyetlere Katılım Engelleri

\begin{tabular}{lllllll}
\hline & $\mathrm{N}$ & $\overline{\boldsymbol{x}}$ & Standart Sapma & $\mathrm{t}$ & $\mathrm{df}$ & $\mathrm{p}$ \\
\hline Kadın & 130 & 3,8677 &, 55100 & \multirow{2}{*}{3,885} & 2 & 276 \\
\hline Erkek & 148 & 3,5802 &, 66680 & 0,000 \\
\hline
\end{tabular}

Araştırma katılımcıları rekreatif faaliyet katılım engelleri algısı ortalamasının kadınlarda ( $\bar{x}=3,8677$ ) ve erkeklerde ( $\bar{x}=3,5802$ ) olduğu saptanmıştır. Anlamlılık için yapılan $\mathrm{t}$ testine göre, öğrencilerin cinsiyetleri ile rekreatif faaliyet katılım engelleri algıları arasındaki fark $(t=3,885, p<0,05)$ anlamlı bulunmuştur. Bu durumda, kadın öğrencilerinin rekreatif faaliyet katılım engelleri algılarının daha yüksek olduğu tespit edilmiştir.

Tablo 4. Turizm Rehberliği Öğrencilerinin Uyruklarnna Göre Rekreatif Faaliyetlere Katılim Engelleri

\begin{tabular}{lllllll}
\hline & $\mathrm{N}$ & $\bar{x}$ & Standart Sapma & $\mathrm{t}$ & $\mathrm{df}$ & $\mathrm{p}$ \\
\hline T.C. & 265 & 3,7178 &, 63793 & \multirow{2}{*}{, 380} & \multirow{2}{*}{276} & \multirow{2}{*}{0,704} \\
\hline Diğer & 13 & 3,6496 &, 47840 & & & \\
\hline
\end{tabular}

Araştırma katılımcları rekreatif faaliyet katılım engelleri algısı ortalamasinin T.C. uyruklu olanların ( $\bar{x}=3,7178)$ ve yabanc uyruklu olanların ( $\bar{x}$ $=3,6496$ ) olduğu saptanmıştır. Anlamlılık için yapılan $\mathrm{t}$ testine göre, öğrencilerin cinsiyetleri ile rekreatif faaliyet katılım engelleri algiları arasındaki fark $(\mathrm{t}=, 380, \mathrm{p}>0,05)$ anlamlı bulunmamıştır. Bu durumun araştırmaya katılan yabancı uyruklu öğrencilerinin sayılarının azlığından kaynaklandığı söylenebilir. 
Tablo 5. Turizm Rehberliği Öğrencilerinin Yaşlarna Göre Rekreatif Faaliyetlere Katılım Engelleri

\begin{tabular}{llllll}
\hline & Kareler Toplamı & df & Kare Ortalaması & F & p \\
\cline { 1 - 4 } Guruplararası & 4,715 & 14 &, 337 & & \multirow{2}{*}{, 485} \\
\cline { 1 - 5 } Gruplariçi & 50,277 & 147 &, 342 & \\
\cline { 1 - 5 } Toplam & 54,993 & 161 & & & \\
\hline
\end{tabular}

Tablo 5'e göre katılımcların rekreatif faaliyet katılım engelleri algılarının yaş gurubuna göre farklılık göstermediği ortaya çıkmaktadır $\left(\mathrm{F}_{(14 ; 147)}\right)=$ $0,985, \mathrm{p}>0,05)$.

Tablo 6. Turizm Rehberliği Öğrencilerinin Sınıflarna Göre Rekreatif Faaliyetlere Katılım Engelleri

\begin{tabular}{llllll}
\hline & Kareler Toplamı & $\mathrm{df}$ & Kare Ortalaması & $\mathrm{F}$ & $\mathrm{p}$ \\
\hline Guruplararası & 1,911 & 3 &, 637 & & \\
\cline { 1 - 4 } Gruplariçi & 104,794 & 267 &, 392 & \multirow{2}{*}{1823} \\
\cline { 1 - 5 } Toplam & 106,705 & 270 & & & \\
\hline
\end{tabular}

Tablo incelendiğinde katılımcların rekreatif faaliyet katılım engelleri alg1larının sınıf guruplarına göre farklılık göstermediği ortaya çıkmaktadır ( $F$ $(3 ; 267)=1,623, \mathrm{p}>0,05)$.

Tablo 7. Turizm Rehberliği Öğrencilerinin Aylık Gelir Dïzeylerine Göre Rekreatif Faaliyetlere Katılim Engelleri

\begin{tabular}{llllll}
\hline & Kareler Toplamı & $\mathrm{df}$ & Kare Ortalaması & F & $\mathrm{p}$ \\
\hline Guruplararası & 3,573 & 4 &, 893 & & \multirow{2}{*}{2,259} \\
\cline { 1 - 5 } Gruplariçi & 105,996 & 268 &, 396 & & \\
\cline { 1 - 5 } & 109,569 & 272 & & & \\
\hline
\end{tabular}

Tablo incelendiğinde katılımcların rekreatif faaliyet katılım engelleri alg1larının aylık gelir durumu guruplarına göre farklılık göstermediği ortaya çıkmaktadır $(\mathrm{F}(4 ; 268))=2,259, \mathrm{p}>0,05)$.

Tablo 8. Turizm Rehberliği Öğrencilerinin Rekreatif Faaliyetlerine Göre Rekreatif Faaliyetlere Katılım Engelleri

\begin{tabular}{llllll}
\hline & Kareler Toplamı & $\mathrm{df}$ & Kare Ortalaması & $\mathrm{F}$ & $\mathrm{p}$ \\
\cline { 1 - 4 } Guruplararası & 2,567 & 2 & 1,284 & & \\
\cline { 1 - 5 } Gruplariçi & 107,674 & 275 &, 392 & \multirow{2}{*}{039} \\
\cline { 1 - 5 } & 110,241 & 277 & & \\
\hline
\end{tabular}


Tablo 8 incelendiğinde katılımclların rekreatif faaliyet katılım engelleri algılarının rekreatif faaliyet guruplarına göre farklılık gösterdiği ortaya çıkmaktadır $(\mathrm{F}(2 ; 275))=3,278, \mathrm{p}<0,05)$. Bu farklılaşmanın ayrıntıları Tablo 9'da daha net görülebilmektedir.

Tablo 9. Turizm Rehberliği Öğrencilerinin Rekreatif Faaliyet Katılım Engelleri Puanlarnnın Rekreatif Faaliyetlerine Göre Dağılımı

\begin{tabular}{llllllll}
\hline & $\mathrm{N}$ & $\overline{\boldsymbol{X}}$ & $\begin{array}{l}\text { Standart } \\
\text { Sapma }\end{array}$ & $\begin{array}{l}\text { Standart } \\
\text { Hata }\end{array}$ & Min. & Mak. \\
\hline Rekreatif & Yok & 195 & 3,692 &, 64550 &, 04623 & 1,00 & 5,00 \\
\cline { 2 - 8 } Faaliyet & Eğlence $\backslash$ Gezi Faaliyetleri & 53 & 3,890 &, 54947 &, 07548 & 2,04 & 5,00 \\
\cline { 2 - 8 } $\begin{array}{l}\text { Katılım } \\
\text { Engelleri }\end{array}$ & Spor Faaliyetleri & 30 & 3,548 &, 61980 &, 11316 & 1,57 & 4,57 \\
\cline { 2 - 8 } & Toplam & 278 & 3,714 &, 63086 &, 03784 & 1,00 & 5,00 \\
\hline
\end{tabular}

Tablo 9'a göre, turizm rehberliği öğrencilerinin katıldıkları rekreatif faaliyetlere göre rekreatif faaliyet katılım engelleri sonuçlarında farklılaşma olmakla birlikte, herhangi bir faaliyete katılmayanların $(\bar{x}=3,692)$, eğlence $\backslash$ gezi faaliyetlerine katılanların $(\bar{x}=3,890)$, sportif faaliyetlere katılanların $(\bar{x}$ $=3,548$ ) ortalamaya sahip oldukları görülmektedir. Dolayısıyla eğlence ve gezi faaliyetleriyle ilgilenen öğrenciler, sportif faaliyetlerle ilgilenen öğrencilerden daha fazla rekreatif katılım engeliyle karşılaşmaktadırlar. Diğer yandan herhangi bir rekreatif faaliyete katılmayan öğrencilerin oranının \%70,14 olduğu görülmektedir. Her 3 öğrenciden 2'si rekreatif faaliyetlere katılma olanağı bulamamaktadır.

\section{Kişilik Özellikleri İle Rekreatif Faaliyetlere Katılım Engelleri İlişkisi}

Ölçeklerin ortalama skorları, standart sapmaları ve değişkenler arası korelasyon değerleri Tablo 10'da sunulmuştur.

Tablo 10. Kişilik Özellikleri İle Rekreatif Faaliyetlere Katılım Engelleri Arasındaki İlişki

\begin{tabular}{lcccll}
\hline & $\mathrm{N}$ & $\overline{\boldsymbol{x}}$ & Standart Sapma & $\begin{array}{l}\text { Kişilik } \\
\text { Özellikleri }\end{array}$ & $\begin{array}{l}\text { Rekreatif Faaliyetlere } \\
\text { Katılım Engelleri }\end{array}$ \\
\hline Kişilik Özellikleri & 289 & 3,479 &, 29684 & 1 & 1 \\
\hline $\begin{array}{l}\text { Rekreatif Faaliyetlere } \\
\text { Katılım Engelleri }\end{array}$ & 278 & 3,714 &, 63086 & $\begin{array}{l}, 294^{* *} \\
, 000\end{array}$ & 1 \\
\hline
\end{tabular}

**. Korelasyon 0.01 düzeyinde anlamlıdır. (2-kuyruk). 
Tablo 10'a göre katılımcların kişilik özelliklerinin $(\bar{x}=3,479)$ ve rekreatif faaliyetlere katılım engellerinin ( $\bar{x}=3,714$ ) ortalamalarına sahip olduğu görülmektedir. Kişilik özellikleri ile rekreatif faaliyetlere katılım engelleri arasındaki ilişkiler Pearson korelasyon katsayısı tekniği ile incelenmiştir. Kişilik özellikleri ile rekreatif faaliyetlere katılım engelleri arasında pozitif yönlü anlamlı bir ilişki $(\mathrm{r}=0,294, \mathrm{p}<.01)$ vardır.

Tablo 11. Kişilik Özelliklerinin Rekreatif Faaliyetlere Katılım Engelleri Üzerine Etkisi

\begin{tabular}{|c|c|c|c|c|c|c|c|}
\hline \multirow{2}{*}{ Bağımlı Değişken } & \multirow{2}{*}{ Bağımsız Değişken } & \multicolumn{2}{|c|}{ Anlamlılık } & \multirow{2}{*}{$\mathrm{t}$} & \multirow{2}{*}{$\mathrm{p}$} & \multirow{2}{*}{$\mathrm{F}$} & \multirow{2}{*}{$\mathrm{R}^{2}$} \\
\hline & & $\beta$ & S.Hata & & & & \\
\hline \multirow{6}{*}{$\begin{array}{l}\text { Rekreatif } \\
\text { Faaliyetlere } \\
\text { Katilım } \\
\text { Engelleri }\end{array}$} & Sabit Değer & 1,452 & 436 & 3,328 & 001 & \multirow{6}{*}{6,013} & \multirow{6}{*}{0,083} \\
\hline & Dışadönüklük & ,174 & 105 & 1,653 & , 100 & & \\
\hline & Naziklik & ,251 & ,111 & 2,252 & ,025 & & \\
\hline & Vicdanlılık & ,028 & ,104 & ,271 & ,787 & & \\
\hline & Nevrotiklik & , 186 & 100 & 1,873 & ,062 & & \\
\hline & Açıklık & ,027 & 101 & ,269 & ,788 & & \\
\hline
\end{tabular}

Tablo 11'e göre rekreatif faaliyetlere katılım engelleri algısını etkileyen kişilik özellikleri rekreatif faaliyetlere katılım engelleri düzeyini 0,083 oranında açıklamaktadır $\left(R^{2}=0,083\right)$. Bu sonuca göre öğrencilerin rekreatif faaliyetlere katılım engelleri algılarındaki \%8,3'lük değişim kişilik özellikleri değişkeni tarafından açıklanmaktadır. Ayrıca tabloya göre "naziklik" kişilik özelliğine sahip öğrencilerin diğer kişilik özelliklerine sahip öğrencilere kıyasla daha fazla rekreatif faaliyete katılım engeli algıladığı bulgusu istatistiksel açıdan anlamlı bir $\mathrm{p}$ değerine $(\mathrm{p}<.01)$ sahiptir.

\section{Sonuç, Tartışma ve Öneriler}

Üniversite öğrencilerinin herhangi bir engelle karşılaşmadan rekreatif faaliyetlere katılmaları sosyal ilişkilerini güçlendirmeleri, gelecekte daha verimli, donanımlı ve iletişim becerisi yüksek bireyler olarak topluma katılabilmeleri açısından çok önemlidir. Rekreatif engellerin saptanmasına yönelik çalışmalar daha çok fiziksel unsurların yetersizliği üzerinde durmaktadır. Ancak sadece fiziksel engellerin üzerinde durulması öğrencilerin psikolojik ve kişisel özelliklerinin göz ardı edilmesine yol açmaktadır, dolayısıyla öğrencilerin rekreatif motivasyonlarının nasıl oluştuğu veya fiziksel engellerle bir ilişkisinin olup olmadığı kritik bir hipotez olarak karşımıza çıkmaktadır. Bu çalış- 
mada rekreatif faaliyetlere katılma engellerinin öğrencinin kişilik özellikleriyle bir ilişkisinin olup olmadığ incelenerek kuramda bu yöndeki bir boşluğun doldurulması hedeflenmiştir. Ayrıca rekreatif faaliyetlere katılım konusunda daha fazla sorun yaşayan kişilik özelliklerine sahip öğrencilerin saptanması, okul ve yurt yöneticilerine sorunların çözülmesi noktasında daha etkin pratikler sunmalarına yardımcı olabilecektir.

Araştırma bulgularına göre, Aydın Adnan Menderes Üniversitesi (ADÜ) Turizm Rehberliği Bölümü öğrencilerinin rekreatif faaliyet katılım engelleri algılarının daha yüksek olduğu tespit edilmiştir. Bunun belki de en önemli nedeni ADÜ'lü öğrencilerin Kuşadası'nda olması ve Aydın merkez yerleşkesinden bir buçuk saat uzakta olmalarıdır. Anketlerin uygulanma sürecinde katılımclar, sosyal toplulukların sadece merkez yerleşkede faaliyette bulunma koşulu ile açlmasının önemli bir engel teşkil ettiği yönünde görüşler dile getirmişlerdir. Yine alan yazında benzer şekilde (Tekin, Yıldız, Akyüz ve Uğur, 2007), her iki üniversitede kadın öğrencilerin rekreatif faaliyetlere kattlım engellerinin daha yüksek algılandığı ortaya çıkmıştır. Yabancı uyruklu öğrenci sayısı az olduğu için öğrencilerin uyrukları ile rekreatif faaliyetlere katılım engelleri arasında istatistiksel açıdan anlamlı bir farklılaşma görülmemiştir. Yine aynı şekilde katılımcıların yaşları, aylık gelir düzeyleri ve sınıfları ile rekreatif faaliyetlere katılım engelleri arasında istatistiksel açıdan anlamlı bir farklılaşma görülmemiştir. Çalışma bu açıdan alan yazındaki benzer bir çalışmayı (Müderrisoğlu ve Uzun, 2004) desteklememektedir. Aylık gelirin bir farklılaşma oluşturmaması dikkate değer bir noktadır. Bu bulgu öğrencilerin daha çok pasif rekreasyonu tercih ettikleri veya yerleşke dışındaki faaliyetlere katılma konusunda isteksiz oldukları şüphesini doğurmaktadır.

Rekreatif faaliyetlere göre rekreatif faaliyet katılım engellerine yönelik bulgular incelendiğinde karşımıza çıkan en çarpıcı sonuç herhangi bir rekreatif faaliyete katılmayan öğrencilerin oranının \%70,14 olmasıdır yani her 3 öğrenciden 2'si rekreatif faaliyetlere katılma olanağı bulamamaktadır. Diğer yandan eğlence ve gezi faaliyetleriyle ilgilenen öğrenciler, sportif faaliyetlerle ilgilenen öğrencilerden daha fazla rekreatif katılım engeliyle karşılaşmaktadırlar. Bunun nedeni de sportif faaliyetlerle ilgili rekreasyon faaliyetlerinin sağlanmasında üniversitelerin daha organize ve etkin olmaları olabilir. Ĕglence ve gezi faaliyetleri öğrencilerin ve/veya hocaların inisiyatif almalarını, aktif kişilik özelliği ve güdülenme gerektiren faaliyetlerdir. 
Araştırma bulgularına göre bir bütün olarak kişilik özellikleri ile rekreatif faaliyetlere katılım engelleri arasında pozitif yönlü anlamlı bir ilişki vardır. Kişilik özellikleri ayrı ayrı incelendiğinde nazik kişiliği olan öğrencilerin; nevrotik, açık, vicdanlı ve dışadönük kişilik yapısı olan öğrencilerden daha fazla rekreatif faaliyet engeli algısına sahip olduğu bulgusu istatistiksel açıdan anlamlı bir değere sahiptir. Bunun nedeni nazik kişilik özelliğinde olan öğrencilerin daha çekingen veya içedönük yapıda olmaları ile açıklanabilir.

Bu bulgular doğrultusunda araştırmanın sonuçlarından pratik olarak yararlanabilecek akademik yöneticilere, üniversite öğrencilerine ve gelecekteki araştırmacılara aşağıdaki öneriler sunulmuştur:

\section{Akademik Yöneticilere Öneriler}

- Akademik yöneticiler rekreasyon olanaklarını sunarken, eğlence ve gezi faaliyetleri ile ilgilenen öğrencilerin sorunları ve taleplerini öncelikli olarak değerlendirmeye almalıdır. Öğrenci gezilerine katılım göstermeye ilgili olan hocaların cesaretlendirmeleri veya onlara maddi bazı olanaklar sunmaları öğrencilerin daha etkin olmalarını sağlayabilir.

- Profesyonel kişilik testleri ile öğrencilerin kişilik özellikleri saptanabilir ve özellikle nazik kişiliğe sahip öğrencilerin rekreatif faaliyetlere katılma yönünde motive edilmesi öncelikli eylem olarak hedeflenebilir.

- Öğrencilerin \%70'inin bir rekreatif faaliyetle ilgilenmiyor olması, onların "üniversiteyi sadece kuramsal ve pratik eğitim kurumu olarak görmelerinden mi kaynaklanmaktadır? yoksa başka yapısal nedenler mi bu sonucu ortaya çıarmaktadır?" sorusu dikkate alınmalıdır. Öğrencilere üniversite eğitiminin sadece derse girip çıkmaktan ibaret olmadığı bunun da ötesinde bir kişisel gelişim kurumu olduğu algısı vurgulanmal1dir.

\section{Gelecekteki Araştırmacılara Öneriler}

- Bu çalışmada alan yazındaki diğer çalışmaları da destekleyici bir şekilde kadın katılımcıların daha çok rekreatif faaliyetlere katılım engeli olduğu saptanmıştır. Bu noktada gelecekteki araştırmacilara sadece kadın katılımcların dahil edileceği nicel araştırmalar yapmaları veya kadın katılımcların rekreatif faaliyet katılım engellerinin, kadınlara yönelik durumsal 
şartlarının yeniden incelenebileceği keşifsel ve derinlemesine nitel çalışmalar yapmaları önerilebilir.

- Erasmus gibi öğrenci değişim programları ile gün geçtikçe daha fazla sayıda yabancı uyruklu öğrenci üniversitelerde öğrenim görmektedir. Sadece yabancı uyruklu öğrencilerin rekreatif faaliyetlerine katılım engellerinin araştırılması kurama önemli katkılar sağlayacaktır ve gelecekteki araştırmacılara bu yönde çalışmaları önerilebilir.

\section{Öğrencilere Öneriler}

- Bu araştırmaya katılan öğrencilerin ortalama \%70'i bir rekreatif faaliyetle ilgilenmediğini belirtmiştir. Öğrenciler üniversite eğitimini kuramsal bilgi edinmenin dişında bedensel ve düşünsel faaliyetlere katılmak suretiyle kişisel yetenekleri geliştirme firsatı olan bir yer olarak değerlendirmelidirler.

- Rekreatif faaliyetlere katılım engelleri algısı yüksek olan öğrenciler bu engellerini yönetimle paylaşmalı ve aktif katılımcılar olma noktasında daha istekli olmaya çalışmalıdırlar. 
EXTENDED ABSTRACT

\title{
The Relationship Between Personality Characteristics of Tourism Guidance Department Students and Barriers to Participation in Recreational Activities
}

\author{
* \\ Ülker Çolakoğlu - Hakan Atay - Gülseren Yurcu \\ Adnan Menderes University, Akdeniz University
}

It is difficult to determine when personality was first discussed as a scientific concept. Personality was handled for the first time in terms of human's immoral behavior. Later, in psychology, man's unobservable behaviors are handled with his inner impulses and motives. With the developments in social sciences, it has been determined that hereditary characteristics and environmental factors also have an effect on personality. Personality briefly consists of the sum of the biological and psychological features of a person. The emotions, motives, abilities, behaviors, desires and habits are the elements which are determine the personality.

Recreation is the activities that people do in their spare time to rest and have a good time. These events can be active or passive. Examples of active recreation activities are football, basketball, tennis, climbing the mountain. Passive recreation can be shown as camping, barbecue, visiting natural parks and nature trips. Simply, reading a book in one's spare time is a passive recreation activity. There may be some obstacles to people in participating in recreational activities. Some of these obstacles are the person's physiological disabilities, insecurity, negative economic conditions, and limited circle of friends. From the area of university education, it is seen that previous studies are focused more on environmental factors. Insufficient social facilities of universities, students dislike campus, insufficient recreation areas, lack of recreation areas, lessons during activity hours, economic problems, friend incompatibilities, transportation problems, lack of social environment can be considered among the environmental obstacles to participation in recreational activities. Low income level and gender negatively affect participation in recreational activities. For example, female students prefer to participate in passive 
recreational activities, while male students prefer to participate in active recreational activities.

On the other hand, it is an important research question whether the personality traits of a student have an impact on the participation of recreational activities. Identifying students with personality traits who have more problems in participating in recreational activities can help school and dormitory administrators offer more effective practices for solving problems. The aim of this study is to reveal the relationship between the personality traits and demographic factors of the Tourism Guidance students and the barriers to participation in recreational activities. Quantitative research method was used in the research process. The research population consists of the students of two public universities. Tourism guidance departments of two faculties has been investigated and compared together. As research sample, a questionnaire was applied to 289 students. The survey technique was preferred because it allows many participants to reach it in less time and with less cost. Personality Traits and Recreative Activity Participation Barriers were used to collect data. Descriptive statistics, $\mathrm{t}$ test, ANOVA, correlation and regression statistics were used in data analysis. According to the results of the research, it was concluded that the perceptions of students' participation barriers to recreational activities differ according to the variables of school, gender and recreational activity; but not according to the variables of nationality, age, class and income. In addition, there is a positive relationship between personality traits and barriers to participation in recreational activities. It has been determined that students with gentle personality traits have higher perceptions of recreational activity participation barriers.

According to the research findings, Aydin Adnan Menderes University (ADU) Tourism Guidance Department students were found to have higher perceptions of recreational activity participation barriers. Perhaps the most important reason for this is that students with ADU are live in Kuşadası and they are one and a half hours away from Aydin central campus. During the implementation of the questionnaires, the participants expressed their opinions that the opening up of social communities on condition that they operate only in the central campus is an important obstacle. It was revealed that the obstacles of female students to participate in recreational activities were perceived higher in both universities. Since the number of foreign students is 
low, there is no statistically significant difference between students' nationalities and barriers to participation in recreational activities. Likewise, no statistically significant difference was observed between the ages, monthly income levels and classes of the participants and the barriers to participation in recreational activities.

It is noteworthy that monthly income does not create a differentiation. This finding raises the suspicion that students prefer passive recreation more or are reluctant to participate in activities outside the campus. The most striking result is that the rate of students who do not participate in any recreation activity is \%70. The reason for this may be that universities are more organized and effective in providing sportive activities which needs to be done in campus. Recreational and excursion activities are activities that require students and/or teachers to take initiative, active personality trait and motivation. University administrators should consider the demands of students who are interested in excursions and entertainment activities first. Personality types of students can be determined through tests that analyze personality traits. It should be taken into account why the majority of students are not involved in recreation activities.

\section{Kaynakça / References}

Balcı, V. ve İlhan, A. (2006). Türkiye'deki üniversite öğrencilerinin rekreatif etkinliklere katılım düzeylerinin belirlenmesi. Spormetre Beden Eğitimi ve Spor Bilimleri Dergisi, 4(1),11-18.

Buss, A. H. ve Plomin, R. (2014). Temperament (PLE Emotion) early developing personality traits. Psychology Press. Taylor \& Francis Group.

Demirel, M., Harmandar, D. (2009). Üniversite öğrencilerinin rekreasyonel etkinliklere katılımlarında engel oluşturabilecek faktörlerin belirlenmesi. Uluslararast Insan Bilimleri Dergisi, 6(1), 838-846.

Digman, J. M. (1989). Five robust trait dimensions: Development, stability, and utility. Journal of Personality, 57(2), 195-214.

Driskell, J. E., Hogan, J., Salas, E. ve Hoskin, B. (1994). Cognitive and personality predictors of training performance. Military Psyhology, 6(1), 31-46.

Ekinci, N. E., Kalkavan, A., Gündüz, B., Üstün, Ü. D. (2014). Üniversite öğrencilerinin sportif ve sportif olmayan rekreatif etkinliklere katılmalarına engel olabilecek unsurların incelenmesi, Sportif Bakış: Spor ve Eğitim Bilimleri Dergisi, 1(1),1-13. 
Goldberg, L. R. (1990). An alternative "Description of personality": The Big-five factor structure. Journal of Personality and Social Psychology, 59, 1216-1229.

Gürbüz, B., ve Karaküçük, S. (2007). Boş zaman engelleri ölçeği-28: Ölçek geliştirme, geçerlik ve güvenirlik çalışması, Gazi Beden Eğitimi ve Spor Bilimleri Dergisi (Gazi BESBD), XII(1), 3-10.

Hair, J.F. Jr., Anderson, R.E., Tatham, R.L., ve Black, W.C. (1995). Multivariate data analysis with readings. 4th ed. Prentice-Hall International Inc..

Horzum, M. B., Ayas, T. ve Padır, M. A. (2017). Beş faktör kişilik ölçeğinin Türk kültürüne uyarlanması. Sakarya University Journal of Education, 7(2), 398-408.

John, O. P. ve Srivastava, S. (1999). Handbook of personality: Theory and research. NY: The Gulliford Press, New York.

Karaküu̧ük, S. (1999). Rekreasyon, boş zaman değerlendirme. Ankara:Gazi Kitabevi.

Kavirayani, K. (2018). Historical perspectives on personality:The past and current concept: The search is not over yet. History Article, 6(1), 180-186.

Kılıç, M. ve Şener, G. (2013). Üniversite öğrencilerinin rekreasyon etkinliklerine katılımlarındaki sosyolojik etkenler ve yapısal kısıtlamalar. Yükseköğretim ve Bilim Dergisi, 3(3), 220-227.

Köknel, Ö. (1984). Kişilik. Altın Kitaplar Yayınevi, İstanbul.

Lin, Y. J. (1984). Study on recreation site choice behavior. City and Planning,10,33-49.

Mansuroğlu, S. (2002). Akdeniz üniversitesi öğrencilerinin serbest zaman özellikleri ve dış mekan rekreasyon eğilimlerinin belirlenmesi. Akdeniz Üniversitesi Ziraat Fakültesi Dergisi, 15(2), 53-62.

Matthews, G., Deary, I. J. ve Whiteman, W. C. (2003). Personality traits (2nd Edition), Cambridge University Press, Trumpington Street, Cambridge, United Kingdom.

McAdams, D. P. (1997). The conceptial history of personality psychology. (Eds: Hogan, R., Johnson, J., Briggs, S.) Handbook of Personality Psychology içinde (s. 43-59) Academic Press. San Diego, California, US.

McCrae, R. R. ve Costa, P. T. (1990). Personality in adulthood (1st Edition), Guilford Press: New York.

McCrae, R. R. ve Costa, P. T. (2008). The five-factor theory of personality. O. P. John, R. W. Robins, \& L. A. Pervin (Eds.), Handbook of Personality: Theory and Research içinde(3. ed., s.. 182-207). Guilford Press: New York.

Mischel, W. (1968). Personality and assesment. Hoboken, NJ, US: John Wiley \& Sons Inc. Morgan, C. T. (1998). Psikolojiye giriş. Ankara:Hacettepe Üniversitesi Psikoloji Bölümü Yayınları. 
Müderrisoğlu, H., Kutay, E. L. ve Eşen, S. Ö. (2005). Kırsal rekreasyonel faaliyetlerde kisitlayıcılar. Tarm Bilimleri Dergisi, 11(1), 40-44.

Müderrisoğlu, H. ve Uzun, S. (2004). Abant İzzet Baysal Üniversitesi orman fakültesi öğrencilerinin rekreasyonel eğilimleri. Süleyman Demirel Üniversitesi Orman Fakültesi Dergisi, 2, 108-121.

Nias D. K. B. (1985). Personality and recreational behaviour. Kirkcaldy B.D. (eds) Individual Differences in Movement. Springer: Dordrecht

Özarslan, M. (2010). Örgütlerde iş tatmini ve kişilik tipi ilişkisi. Selçuk Üniversitesi, Sosyal Bilimler Enstitüsü, İşletme Anabilim Dalı. Yayınlanmamış Doktora Tezi, Konya.

Schwilgin, F. A. (1974). Town planning guidelines.Department of Public Works,Ottowa. Slavson, S. R. (1948). Recreation and the total personality. New York: Association Press.

Tabachnick, B. G., Fidell, L. S. (2013). Using multivariate statistics. Boston, Pearson

Taggar, S., Hackett, R., Saha, S. (1999). Leadership emergence in autonomous work teams: Antecedents and outcomes. Personnel Psychology, 52(4), 899-926.

Tekin, M., Yıldız, M., Akyüz, M. ve Uğur, O. A. (2007). Karaman Yüksek Öğrenim Kredi Ve Yurtlar Kurumunda kalan üniversite öğrencilerinin rekreatif etkinliklere katılım ve beklentilerinin incelenmesi. Erzincan Eğitim Fakültesi Dergisi, 9(1), 121-135.

Tınar, M. Y. (1999). Çalışma yaşamı ve kişilik. Mercek Dergisi, 14, Mess Yayınları. Tütüncü, Ö., Aydın, İ., Küçükusta, D., Avcı, N. ve Taş, İ. (2011). Üniversite öğrencilerinin rekreasyon faaliyetlerine katılımını etkileyen unsurların analizi. Hacettepe Journal of Sport Sciences, 22(2), 69-83.

Yelboğa, A. (2006). Kişilik özellikleri ve iş performansı arasındaki ilişkinin incelenmesi. İş Güç Endüstri İlişkileri ve Insan Kaynakları Dergisi, 8(2), 196-211.

Yerlisu Lapa, T. ve Ardahan, F. (2009). Akdeniz Üniversitesi öğrencilerinin serbest zaman etkinliklerine katılım nedenleri ve değerlendirme biçimleri. Hacettepe Journal of Sport Sciences, 20(4), 132-144.

Youn, S., Faber, R. J. (2000). Impulse buying: Its relation to personality traits and cues. Advances in Consumer Research, 27, 179-185.

\section{Kaynakça Bilgisi / Citation Information}

Çolakoğlu, Ü., Atay, H. ve Yurcu, G. (2020). Turizm rehberliği bölümü öğrencilerinin kişilik özellikleri ile rekreatif faaliyetlere katılım engelleri ilişkisi. OPUS-Uluslararası Toplum Araştırmaları Dergisi, 15(26), 4386-4407. DOI: 10.26466-/opus.634350 